\title{
La investigación cualitativa y el enfrentamiento armado en Guatemala
}

\author{
Qualitative research and the Guatemalan Civil War
}

\author{
Ricardo Falla, SJ.
}

*Autor a quien se dirige la correspondencia: rfallasj@gmail.com

Discurso presentado como Lección Inaugural 2015 de la Dirección General de Investigación de la Universidad de San Carlos de Guatemala el 5 de febrero de 2015

$\mathrm{M}$ e pidieron que desarrollara en esta conferencia inaugural mi experiencia de investigación sobre el enfrentamiento armado en Guatemala. Se menciona en el título la palabra "cualitativa", pero, aunque lo que describiré es una experiencia de investigación cualitativa, no voy a teorizar sobre ella, ni quisiera daré recetas de cómo realizarla: solo voy a reflexionar al respecto, según lo explico. Daré mi experiencia siguiendo el género literario de la narrativa. Ustedes, si tienen paciencia, pueden escuchar y sacar provecho de lo que más les llame la atención. Tampoco quisiera polemizar sobre la supremacía de la investigación cualitativa frente a la cuantitativa. Bastantes banderas ideológicas existen que nos dividen para añadir otra. El corazón de la investigación cualitativa reside en acercarnos a la visión de las personas, grupos y sociedades que estamos estudiando. Es una manera de entrar a conocer cómo ellas entienden su vida y sus cambios. Pero nos hace falta cuantificar los hechos con la ayuda de la mirada cualitativa para que las preguntas a cuantificar sean relevantes a lo que se desea saber.

Un tema parecido se me pidió desarrollar para finalizar el Congreso de Antropología Social y Etnología en la Ciudad de México en el año 2010. Esa ponencia pueden encontrarla en el primer volumen de la colección que estamos publicando que se llama $\mathrm{Al}$ atardecer de la vida... Voy a seguir algo del esquema que presenté allí, pero no voy a repetirla. También haré referencia al volumen tercero de la misma colección que está saliendo de prensa en estos días, pero que lamentablemente no pudimos traer por retrasos en la imprenta. Ese volumen, como el primero, está editado mancomunadamente por la Asociación para el Avance de la Ciencias Sociales (AVANCSO), la Universidad Rafael Landívar (URL) y la Editorial de la Universidad de San Carlos. Se llama, Ixcán: El campesino indigena se levanta (1966 a 1982). Es el resultado de una larga investigación, precisamente sobre el tema que me pidieron de cómo el pueblo del Ixcán se levantó para apoyar a la revolución durante esos años.

Sin embargo, ese volumen no es una reflexión sobre el proceso mismo de la investigación. Lo que diré aquí de alguna forma puede servir de introducción a ese texto. Este volumen fue redactado antes del libro que ustedes conocen de Masacres de la selva y sirvió de base para publicar ese texto en forma resumida en 1992. El volumen al que me refiero no se pudo publicar entonces por la peligrosidad que significaba.

La estructura de esta ponencia seguirá el orden como se desenvuelve una investigación, desde su origen hasta su término. La he divido en cuatro fases: (1) selección del tema de investigación, (2) recolección de datos, (3) el análisis y sistematización y (4) la redacción. Se podrían añadir también la publicación, la promoción, la distribución y la reacción que se genera. Esto será el cuerpo de la ponencia. Añadiré algunas conclusiones de posible aplicación a situaciones de la violencia en la actualidad, especialmente del narcotráfico. Ojalá no me vaya a estar esperando un sicario a la vuelta de la esquina.

\section{a. Selección del tema de investigación}

Entonces, primero: ¿cómo se selecciona el tema de la investigación? Lo que quiero decir es que no es el producto de una elección fría desde un gabinete. Al menos no fue así en el caso que me han pedido contar. Hubo un proceso de varios años de acompañamiento al proceso nacional, el cual se fue haciendo cada vez más violento. Cuando hice el trabajo de campo en Quiché para Quiché rebelde, en 1970, se oía que las Fuer- 


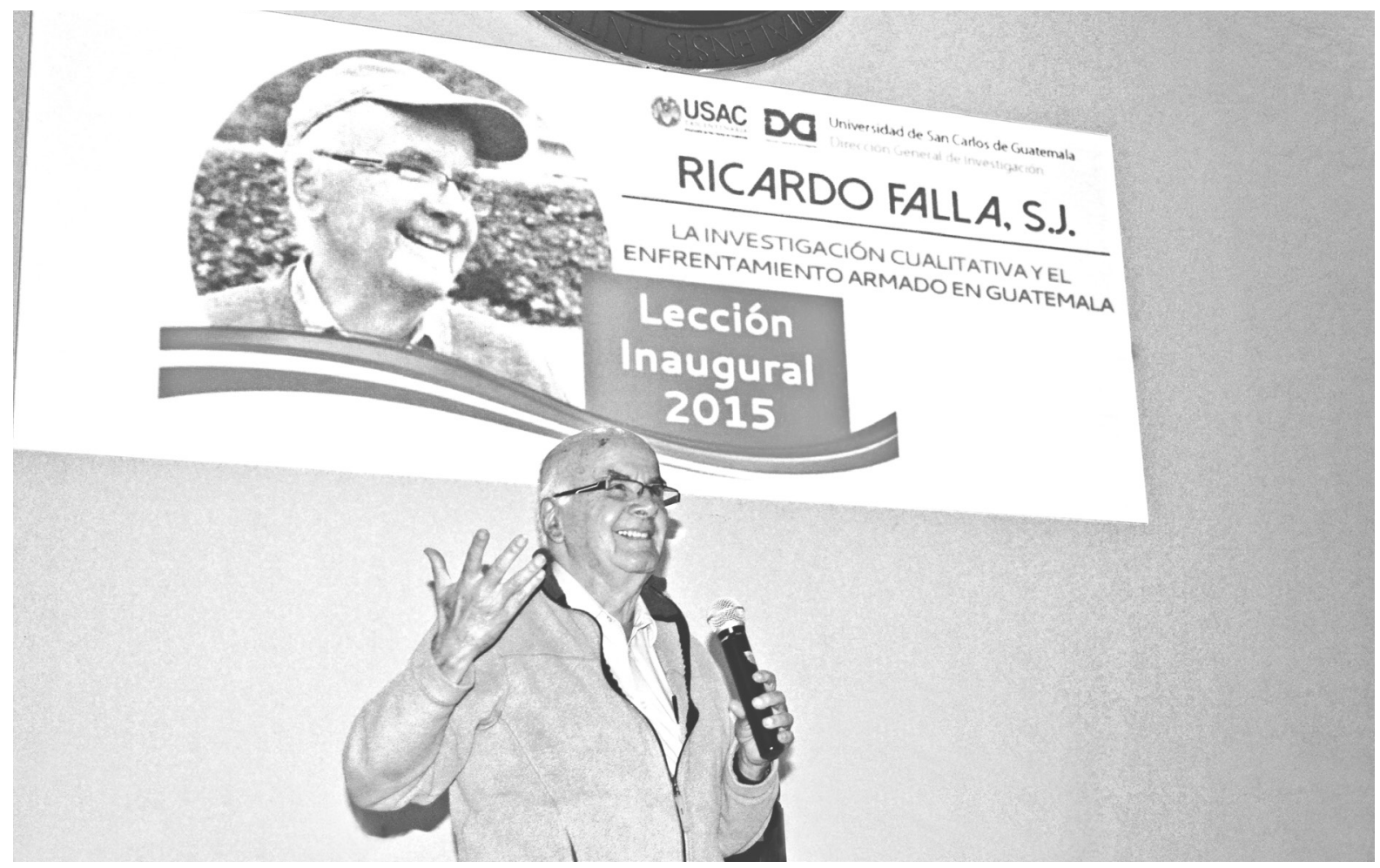

Figura 1. El jueves 5 de febrero, en el Aula Magna "Iglú" de la Universidad de San Carlos de Guatemala el Dr. Ricardo Falla dictando la conferencia.

zas Armadas Rebeldes (FAR) habían hecho una incursión en el norte del departamento. Yo me pregunté, ¿y por qué la revolución ha pegado en territorio ladino o en territorio de selva y no así en un área densamente poblada del mundo indígena? Di unas respuestas que pueden ser leídas en ese libro, pero realmente no tenía yo idea de cómo funcionaba la organización política armada en zona indígena campesina, profundamente identificada con su cultura de siglos.

Pero pasaron unos años. Conocí a Joaquín Noval, quien me llevó a finales de 1975 a conocer la zona fronteriza de San Marcos donde operaba lo que él llamaba "La guerrilla de la milpa". Era el aparato de frontera del Partido Comunista (PC) con una visión de semilla revolucionaria más amplia. Allí estuve cruzando el Suchiate a nado de noche y entrevistando a mucha gente. Pero realmente no supe hacerlo. Quiero decir, no supe cómo recoger la información para que fluyera, a pesar de que había confianza en los informantes. No tenía un marco de referencia, ni menos un marco teórico: no tenía lo que llamo el hilo que seguir.

Una experiencia de investigación ulterior fue cuando un compañero sacerdote me contó "con pelos y señales" la toma de Nebaj por el Ejercito Guerrillero de los Pobres (EGP) en 1979, y pude estar en Nebaj para enterarme, desde la casa parroquial, cómo se estaba gestando el movimiento armado, apoyado por el pueblo ixil. Allí entendí algo. Lo redacté en México, en 1979, y se lo di a leer a Alaíde Foppa. Ella también me dijo lo mismo. Ahora entiendo. Esa es señal de una buena investigación: comunicar inteligibilidad. Pero era nada más que un luzazo, una parte de un proceso.

Después me tocó trabajar con el Ministerio de Reforma Agraria (MIDINRA) en Nicaragua, en 1980, y allí aplicamos los métodos que íbamos aprendiendo de la Contra (contrarrevolucionarios). Un compañero se fue a Jinotega a investigar una banda conformada por proletarios agrícolas del café y yo me fui a Estelí a investigar otra de hijos de pequeños campesinos minifundistas también del café. Fueron las semillas de la Contra, las primeras bandas contrarrevolucionarias, la del Pocoyo y la de Dimas. Por supuesto, el Ejército Sandinista se las "quebró", pero nosotros fuimos detrás recogiendo los restos para ver cómo en la Nicaragua tan revolucionaria, se estaba dando ese caldo de cultivo entre la población civil. Allí ya tuvimos el hilo conductor, el porqué: ¿por qué esa población de zona cafetalera se había levantado contra el Frente Sandinista? 
Por último, desde Nicaragua organizamos la vuelta a Guatemala y como primer tanteo viajé a México para acercarme a la frontera con Guatemala en Chiapas donde se encontraban los refugiados guatemaltecos recién salidos de las masacres. Allí tuve la desbordante experiencia de una noche, al escuchar al testigo de la Masacre de San Francisco, Nentón, quien delante de unas 15 personas sobrevivientes, me contó cómo había matado el ejército a cerca de 350 personas en un día. Eso fue en 1982. Fue una investigación de periodista, creo yo, con todos los aciertos de una investigación cualitativa, pero no una investigación a fondo. Allí entendí yo cómo eso, que parecía increible, ciertamente había sucedido. Otra vez, la inteligibilidad. Desde un solo caso, entendí cómo funcionaba el genocidio guatemalteco. Consistía en matar al pueblo hasta la semilla: es decir, hasta los niños, que no podían ser enemigos políticos de una comunidad.

De allí se fue concretando más la selección del tema, porque me pregunté: ¿cómo se llegó hasta este resultado tremendo de la masacre?, ¿cómo se levantó la población de esos lugares para que la reprimieran así? Cuando, por fin, logramos entrar al terreno de guerra, no en Nentón, que había sido vaciado casi completamente por el ejército, sino en Ixcán, yo le propuse al grupo en que íbamos y a la organización guerrillera que nos permitía entrar, investigar los orígenes del moviento social, en esa área de campesinado indígena multilingüe. Como el grupo tenía otros fines, como era de atender pastoralmente a esa población, yo me dediqué a ambas cosas: a atender pastoralmente a la población y a oir de su boca cómo se había originado y desarrollado el levantamiento hasta ser reprimido en las grandes masacres - como la de Nentón- y luego la transformación en una resistencia organizada.

No sé si les ha cansado esta historia, pero en ella se ve, me parece, cómo la selección del tema es un proceso que lleva consigo los siguientes elementos:

- El hilo conductor de la investigación se aclara, es decir, la pregunta que conducirá toda la investigación se cimenta así: ¿cómo se generó todo esto que culminó en las masacres?, ¿cómo la población indígena y campesina se fue levantando?, ¿cómo fue esto posible? Esta pregunta es el hilo conductor.Y el método cualitativo va implícito: hay que estar con ese pueblo que ha sido el sujeto y hacerle la pregunta a él. La cuantificación no se excluye para nada, como el número de víctimas.

- Las razones de la importancia de la investigación se van conociendo: no se trata sólo de la denun- cia de la violación a los derechos humanos para que pare la represión, sino el valor que tiene la comprensión misma del proceso, por las fuerzas que puede desencadenar, no sólo aquí y hoy en Guatemala, sino en otras partes del mundo y en tiempos futuros. Este conocimiento influye en el hilo conductor, por eso dije, que no sólo que se aclara la pregunta, sino se cimenta.

- Se va fortaleciendo la decisión de emprender la investigación y de terminarla, aunque haya riesgos y aunque el tiempo exija constancia.

Unido a este último punto, va el tema del sujeto que respalda la investigación, y en cierta forma participa en ella, aunque no investigue. Puede ser la familia o un sujeto mayor, como la universidad. En mi caso, el sujeto fue un grupito de amigos con quienes entramos al terreno de guerra, pero sobre todo mi grupo de referencia identitario que eran algunos compañeros jesuitas y el superior que me daba una misión de vanguardia. Ninguno de los miembros de estos dos grupos hacía investigación, pero para la decisión de hacerla era importante. Sobre este sujeto, pueden ver el libro reciente de Hernández, (2014).

Si ustedes quieren hacer una investigación sobre el narcotráfico en el terreno donde se mueve, necesitan convicción en la decisión y respaldo moral constante de la familia, de la pareja, de la universidad... No es por aventura o por fuga que vas a hacer eso. Y también necesitas quién te respalde económicamente, porque tendrás que dejar para alimentar a tus hijos, si tienes, y a tu pareja, y necesitas pagar los gastos en que incurras en la investigación. En mi caso, no tenía familia y los gastos eran mínimos, pues durante los casi seis meses de la investigación de campo, la población nos dio de comer.

\section{Recolección de la información}

El trabajo de campo, como decimos los antropólogos, para obtener información acerca de la violencia siempre es arriesgado, porque te juegas la vida, un poco como un reportero de guerra. También es difícil, porque los temas de la violencia se cubren a sí mismos por la dinámica misma de la violencia de ocultamiento o diversión. Piénsese en alguien que quiera investigar en el terreno a los narcotraficantes. Es peligroso y es prácticamente imposible, a no ser que te hagas uno de ellos, te infiltres en ellos, que no es lo que propongo. 
En nuestro caso, la situación en Ixcán era de guerra y persecución. Había ametrallamientos o bombardeos aéreos, pero más peligroso, había operativos de infantería que cruzaban la selva con fin de encontrar a los campamentos de población civil que daban apoyo a la guerrilla. Había que andar en lo que llamaban, "plan de emergencia", es decir, cambiando el campamento de lugar y huyendo para que no nos sorprendiera el que allí era el enemigo: el ejército, tal vez el mejor entrenado para contrainsurgencia en la selva de América Latina.

\section{a. La recolección propiamente tal}

Sin embargo, era posible entrevistar a la población. Digo, "entrevistar", porque estoy ante ustedes en esta ponencia de ciencias sociales. Es el término técnico que se usa. Pero la entrevista era un diálogo o tal vez más un sentarse a oir lo que las personas contaban desde el origen de este levantamiento. Se podía hacer, porque había una red de autodefensa de la población civil en combinación con la guerrilla, cuya táctica principal (la de la población) consistía en ocultamiento bajo la selva, y en fuga ordenada, irse a lugares más profundos de montaña, sin dejar huella. Era una subcultura de resistencia que prescribía no cocinar de día por el humo, esconder la ropa de los claros para que no la identificara el helicóptero, operar la garganta de los gallos, etcétera. Esa protección permitía largos ratos de conversación, tiempos muertos en que la gente no salía a la producción porque el enemigo estaba cerca y había que mantenerse a la espera.

Durante estos ratos había deseo en la población de comunicar sus experiencias y sufrimientos: por qué habían salido de tierra fría a colonizar la selva, cómo se repartieron la tierra, cómo hicieron los primeros contactos con los guerrilleros ingresados de México, cómo se dio la primera represión sangrienta al detectar el ejército su presencia en la selva, etcétera; una historia larga, hasta las grandes masacres de 1982 y la salida de sus pueblos a la montaña a resistir.

El deseo de hablar me pareció que estaba motivado por dos razones principales, una era que se conociera afuera lo que estaba sucediendo para que se detuviera la represión, y otra, una especie de impulso para desahogarse, buscando consolación en alguien que los o las oyera con mucha atención. Había algo de religioso en eso, porque conocían mi identidad de sacerdote (no, mi nombre, pues todos usábamos seudónimos) y los Maryknoll de Huehuetenango habían organizado la colonización y a ellos sentían que se debía que tuvieran tierra. También, el padre Guillermo Woods había muerto en 1977, como todos sostenían, bajado con su avioneta por los soldados que le dispararon.

Además, había confianza de hablar, no sólo deseo. Esto es clave en este tipo de investigaciones sobre la violencia. Porque estábamos en la misma situación de guerra y de destitución, de modo que la situación de inseguridad se convertía en un potente aliciente para hablar. La persona que los escuchaba debía ser amiga, pensaban, pues estaba allí. Esta relación estaba avalada por la guerrilla que había tenido interés, dentro de lo que llamaba Plan Grande ${ }^{1}$, para que hubiera participación explícita de los cristianos en la revolución. Dentro de dicho plan estábamos nosotros allí. El EGP consideraba que la pastoral de acompañamiento fortalecería la resistencia. La investigación que yo hacía, como ya dije, iba bajo el ala de la pastoral y ante la población mi estatus nunca fue como investigador, ni como académico, ni como antropólogo, sino de sacerdote.

Tambien es importante hacer notar cómo la clandestinidad de la información se abrió por la situación de resistencia colectiva frente al ejército. Ordinariamente, más en ese tiempo, era dificilísimo que alguien contara a un investigador su relación con la guerrilla. No sólo porque podría correrse la información para reprimirlo, sino porque la guerrilla misma imponía ese secreto. Pues bien, después de las masacres masivas, como la de Cuarto Pueblo (1982), la población optó por tres caminos. O se volvió a tierra fría o salió al refugio o se quedó en la montaña resistiendo. Esa población en resistencia, como ya dije, toda ella estaba oculta, clandestina, del ejército. Pero curiosamente, al entrar en una clandestinidad colectiva, la clandestinidad interna a esa población se suspendió. Lo único que en las entrevistas se mantenía en secreto era el verdadero nombre de la persona, por si acaso alguien caía en manos del ejército y lo torturaran para saber quién más estaba en la resistencia. Esa supresión de la clandestinidad fue indispensable para la comunicación de datos confidenciales.

En la recolección de la información veo que hubo una evolución. Primero, me encontré completamente desorientado, en cuanto a nombres, lugares, tiempos, etc. Pero poco a poco fui viendo lo que me faltaba por

\footnotetext{
${ }^{1}$ El comandante del EGP lo llamó así en recuerdo al primer sacerdote asesinado en El Salvador (1977) por denunciar a los finqueros de la zona de caña cercana a la capital del país. Se llamaba Rutilio Grande.
} 
averiguar y fui buscando a las personas que podían llenar esos vacíos. Poco a poco se fue haciendo el esquema o mapa de lo que sería la redacción. Porque uno o una investiga para redactar y comunicarse. El criterio para armar ese mapa, en el caso de esta investigación, era el hilo conductor. Este hilo conductor, como ya dije, era una pregunta: ¿cómo comenzó todo esto, cómo se levantó este pueblo? Un hilo conductor muy fácil de sistematizar porque era histórico y lo que hacía falta era entender la dinámica y las etapas.

Además, en la sistematización de la evolución ya entraba un elemento teórico que en este caso era también muy fácil de descubrir: el elemento dialéctico. Era fácil, porque estábamos viviendo una guerra entre dos contendientes armados y la dinámica era de cada vez más agudización. Pero, para no caer en la visión de los dos fuegos y la población civil pasiva, había que ver en cada momento cómo la población había sido activa, indispensablemente activa, hasta poder ser tildada, equivocadamente por el ejército, como población guerrillera. De esa forma, durante la recolección de la información se iba formando en mi cabeza ya una especie de teoría propia, implícita en la experiencia.

Adelanto que mi manera de trabajar no ha sido muy ortodoxa, lo notarán ya los estudiantes y los y las profesoras de investigación. Siempre se insiste que antes de montar tu proyecto de investigación y antes de salir al campo tienes que tener clara tu teoría y tus hipótesis. Yo, probablemente por limitación intelectual propia, siempre he trabajado al revés. Voy al campo con una sospecha de factores que responden a la pregunta planteada, pero no es sino al volver del campo con un material muy grande, cuando me he preguntado, ¿bueno y para entender esto: para darle un orden, una inteligibilidad?, ¿qué teoría me sirve? Hago a la teoría una sirvienta de la experiencia. No al revés. Tal vez para no errar en esta práctica heterodoxa, lo importante es tener dos cosas claras: (1) la pregunta o hilo conductor que va jalando tu investigación y (2) el olfato. Olfato como de perro que va oliendo con un sexto sentido por dónde está la respuesta a la pregunta que te guía. Ese olfato es experiencia de investigación, es teoría implícita, y, dispensen si sueno un poco místico, el nahual que le canta a uno por dentro y que le dice que por allí voy en lo correcto. Para dejar la mística, llamemos a ese nahual, la consonancia, que se percibe no por la inteligencia racional, sino por la inteligencia sentiente, como creo diría el filósofo Zubiri.
Y aquí con esta cuasi digresión estamos cayendo en las riquezas del método cualitativo, el cual no se reduce únicamente a entrevistas, ni a transmisión de información por observación, sino al "conocimiento por ósmosis", como decía Ellacuría, otro filósofo. Esto tiene mucha importancia para la formación integral de la juventud, no sólo para la investigación. Me refiero a la inserción, al estar con las personas, ver (sin registrar en un papel) sus reacciones y dejar que se vayan formando parte de mi persona, sin pretender imitar. Sólo por ósmosis. Así aprende uno a reaccionar de la misma forma que las personas con quien uno convive, a imaginarse cómo en tal situación actuarían, etcétera. Sabe uno o una interpretar espontáneamente sus fuentes de información y por tanto lo que le dicen a uno. De nuevo, por consonancia se detecta en el sentimiento propio la interpretación correcta y la que no lo es porque "me disuena". Ese temblorcillo interno es muy importante aprender a percibirlo. Hay toda una teoría sobre él, pero no me detengo.

Como ven, para la recolección de información el camino fue para mí facilísimo, sin mérito, podríamos decir, sólo dejándome, eso sí, con los ojos bien abiertos, por el río del pueblo que quería expresarse.

¿Qué limitaciones reconozco? Voy a mencionar cuatro. La primera, que esta historia yo no la viví, solo la oi narrada: historia oral. Yo estuve casi seis meses en la montaña. Viví la resistencia después de las masacres, pero no viví ni las masacres, ni el levantamiento previo. En este sentido, no fui un investigador que ejerció la observación participante más que durante la última parte de esta historia: la resistencia. Sin embargo, vivi con el sujeto colectivo que se levantó y que sufrió las masacres (aunque no murió) y por ósmosis, como dije, me ayudo a interpretar las partes de la misma historia que no observé. La segunda, la limitación ideológica. La casi totalidad de mis informantes estaban en contra del ejército, evidentemente porque este nos estaba persiguiendo y había matado a sus familiares. Me falta la visión de la otra cara, la del que se considera vencedor: el ejército. Esperamos que con el tiempo, esta cara oscura de la luna se aclare y nos dé su perspectiva, no sólo la de los jefes, que suelen taparse y mentir, sino de los soldados en campaña. Tercera, la limitación de la lengua. Ese pueblo, como dije antes, provenía de muchos municipios indígenas del altiplano que habían bajado a colonizar la selva desde 1966 . Había siete lenguas mayas además del castellano. Intenté aprender mam, pero no había posibilidad de ósmosis con sólo pueblo mam, porque la movilidad que 


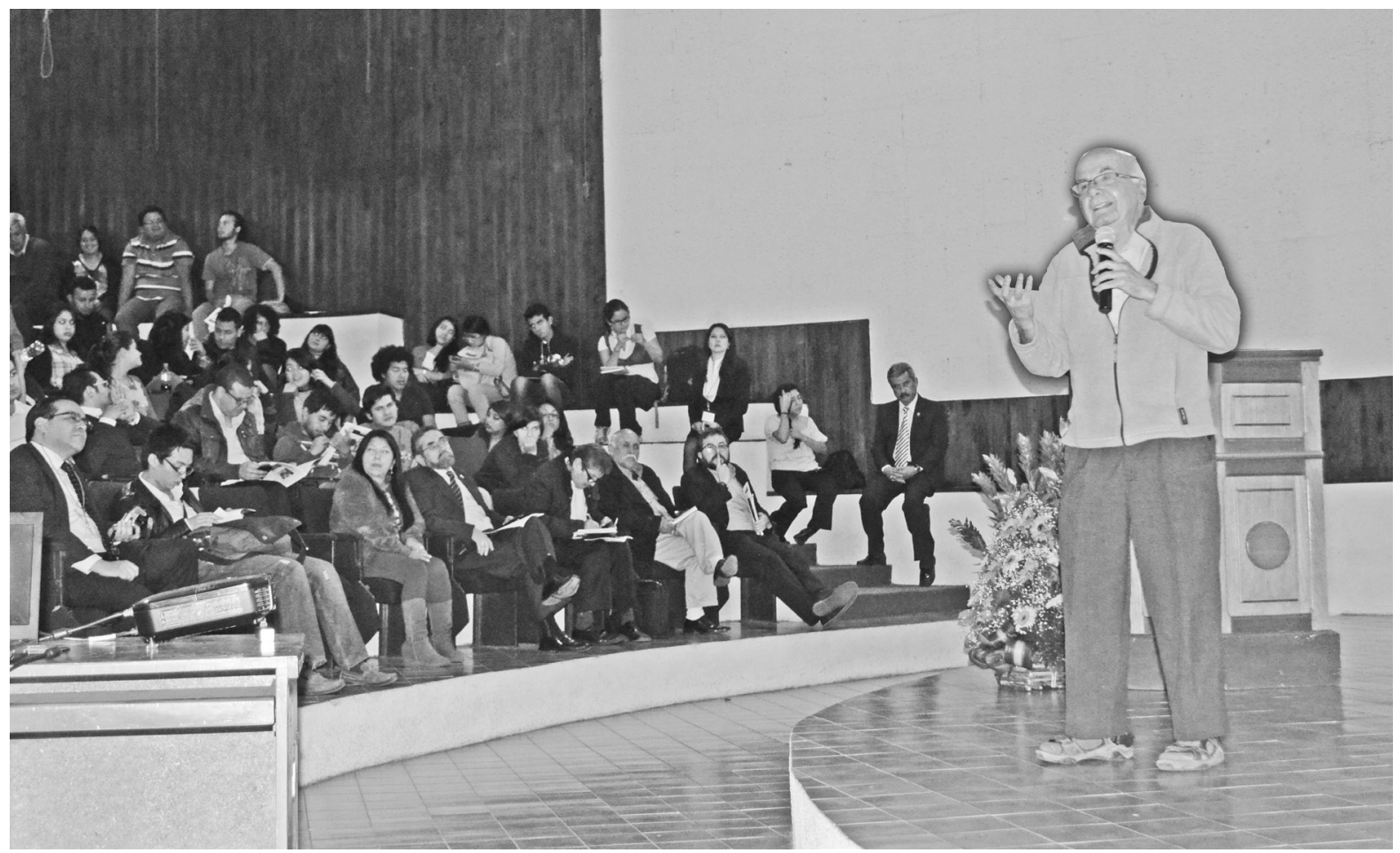

Figura 2. Otra perspectiva de la disertación de Ricardo Falla en el "Iglú".

teníamos nos cambiaba de campamentos preponderantemente mames a campamentos preponderantemente q'anjob'ales, a campamentos preponderantemente kaqchikeles. Yo sabía algo de k'iche', pero allí el k'iche' estaba prácticamente ausente. El multilingüismo, sin embargo, había fomentado el uso del castellano como lengua franca, y en esa nos comunicamos. Y cuarta, que la voz de la mujer no está lo suficientemente representada por la misma razón del idioma. Pero digo la voz, porque con ellas, aunque con pocas palabras, hubo ósmosis. Nos daban de comer junto a su fuego y cruzábamos palabras cargadas de cariño. Recuerdo de una mujer mam de Todos Santos que en el número de tortillas que comía calculaba mi adaptación: mab 'iso$n a$, me decía, no estés triste.

\section{b. Registro de la información}

Hasta aquí hemos tratado el aspecto de la recolección como propiamente tal. Pero otro capítulo se refiere a cómo se registra la información. No usamos grabadora por la imposibilidad de llevar pilas y de contar con casetes. Cientos de cintas habrían supuesto muchas horas de transcripción. En ese tiempo, tam- poco había grabadoras digitales. Por la facilidad del trabajo para el análisis todo lo registré en cinco cuadernos (unas 500 páginas) a mano donde se escribían las entrevistas, y un cuaderno, que le llamo el diario de la selva, donde ponía lo que observaba, lo que sentía y reflexionaba (los cuadernos nos venían del refugio). Al hacer las entrevistas, ponía el seudónimo de la persona, su edad, procedencia de tierra fría, etnia, etcétera, lo principal, y la fecha de la entrevista. Aunque estemos a la carrera, hay que apuntar bien claro y ordenado, lo que permitirá después ordenar la información.

$\mathrm{Y}$ en cuanto al contenido de la entrevista, yo no suelo escribir sólo el esquema de la entrevista sino todo: tengo mala memoria. Escribo casi como en taquigrafía, guardando el vocabulario que usa la gente y el ritmo de la plática. Incluso anotando gestos, como el llanto y la risa. La actitudes son muy importantes: en general, somos aprendices. Entonces, al escuchar estoy como un discípulo ante su maestra con quien se quiere identificar y no le quiere perder una sola palabra, ni un gesto de emoción. Todo es importante para conocer "internamente" - palabra ignaciana- a la fuente del conocimiento, que es una persona que pertenece a un pueblo. 
En cuanto al diario de campo, allí escribía lo que iba pasando día a día y lo que vivíamos. El cuaderno iba en la mochila o en el morral, el diario de campo en la bolsa de la camisa, una hoja doblada que se podía sacar en cualquier momento. Y no se puede omitir la importancia de un buen bolígrafo, que escriba aunque llueva. Estas son tecniquillas, trucos del investigador. Pero no es para que las copien, sino para que las apliquen, si les sirve, el sentido que tienen.

También recogí todo papel que encontraba, hojas sueltas, como listas de masacres, documentos de la organización, partes de guerra a máquina de la misma, cartas de la población en forma de notas envueltas en sobres de nailon, etnomapas, volantes del ejército tirados por el helicóptero, etcétera.

Pero además del cuaderno, protegido por una bolsa de nylon, en la mochila no llevaba más que un nuevo testamento pequeñito, traducción de Oxford en inglés. En el refugio, donde la vida era sedentaria, sí circulaban libros pesados, como la Biblia, entre los refugiados, o un "ladrillo" soviético del marxismo leninismo que una guerrillera me prestó.

\section{c. La seguridad de la información}

La seguridad de la información es muy importante, es decir, que no se pierda, no se decomise, no caiga en manos equivocadas. En parte se resolvía esto por la mala y pequeña letra, muy difícil de descifrar. Hay que proteger al informante, a las personas sobre las que él o ella ha hablado y a uno mismo, especialmente del enemigo. Todos teníamos seudónimos. Esto ayudaba. Pero también había que proteger a informantes críticos de los cuadros guerrilleros. Hubo algunos o algunas. La guerrilla "embuzonaba" mis cuadernos ya llenados. Nunca llevaba más de un cuaderno en la mochila. Ellos conocían los seudónimos y podría haber revancha. O sencillamente, que no se pierdan los cuadernos, que no los capture el ejército (como cuando cayó el buzón de la iglesia y perdí un cuaderno), o que no los queme asustado un compañero que piensa que va a caer el cuaderno en manos del ejército (así perdí un censo de toda la población de las Comunidades de Población en Resitencia [CPR] muy valioso). Esos cuadernos son un tesoro, hasta soñaba con ellos. La guerrilla se encargó de sacarlos de la montaña y trasladarlos a México, donde se me entregaron fielmente.

Si ustedes hacen una investigación sobre la violencia del narcotráfico, cuidado con sus notas de campo, con las fotos del celular, con las conversaciones... cuidado, no sólo ante los grupos adversos que se puedan vengar, sino con los niños que los pueden perder...

\section{Análisis y sistematización}

Ya con los cuadernos en México, se inició esta tercera etapa. Hay que decir que entre análisis y sistematización hay una relación estrecha, porque a la vez que se analiza el material, se va sistematizando y viceversa, también, la sistematización es necesaria para el análisis. Los dos procesos avanzan en relación mutua. Y también, que estos dos procesos van unidos al de la redacción, que tratamos en otra etapa, porque mientras redactas vas analizando y vas encontrando nuevas relaciones. Pero la redacción ya lleva un elemento de comunicabilidad más explícito, porque ya vas pensando en quién te va a leer. Te vas comunicando con un público. No escribes para ti mismo o para ti misma.

\section{a. Lugar de trabajo}

Tal vez no se piensa suficientemente, al preparar una investigación, en cosas aparentemente independientes de ella como los lugares de trabajo y de vida. Al volver de la montaña a la ciudad de México, ¿dónde voy a vivir y dónde voy a trabajar? El sujeto mayor de la investigación era la Compañía de Jesús, y ella me proporcionó una comunidad de compañeros mexicanos con un cuarto y también me facilitó un cuarto $\mathrm{u}$ oficina en una institución adonde me trasladaba en bicicleta a través del tráfico de la gran metrópolis. La oficina era un cuarto sólo para mí, allí me encerraba, como un monje solitario para poder pensar y ver cómo acometer el análisis del material. Además, era un cuarto con llave, donde el material podía estar seguro. El jesuita que dirigía esa institución era un gran amigo y me dio llave de la puerta principal. Yo podía entrar y salir a la hora que quisiera. Y no me cobraba nada. También en la comunidad tenía papeles para que cuando me cansaba de estar en un lado, podía ir al otro. Pero el lugar de trabajo era la institución.

En la ciudad de México había focos de actividades que podían dispersarlo a uno del trabajo de investigación. La solidaridad era muy activa. Me pedían que asistiera a ellos. Podían ser fiestas, podían ser talleres, podían ser misas... El peligro era la dispersión, que es un gran enemigo de la investigación. Procuraba entonces dedicar la mañana a esta y las tardes a divagar un poco. Pero ambas actividades tenían cierta relación, porque la solidaridad era con Guatemala y con los 
refugiados externos e internos, y la investigación era sobre los refugiados internos. En la solidaridad tenía que guardar el secreto de lo que estaba escribiendo. No decía que era sobre el levantamiento y la resistencia, sino sobre los refugiados en general. Ese es el tipo de tensiones que uno tiene que vivir si está trabajando con temas delicados que tocan la violencia.

Digo que la dispersión es enemiga de la investigación. Para superarla hace falta concentrarse, no sólo con la ayuda del local, sino de la intencionalidad que te determinó al seleccionar el tema (vale la pena lo que estás haciendo) y del hilo conductor en el que se ha ido concretando esa intencionalidad en el tiempo del trabajo de campo, la pregunta que decíamos. Pero ahora, al analizar y sistematizar, ese hilo conductor va tomando forma y multiplicándose en miles de preguntas, pero todas relacionadas, y te va jalando mentalmente. Es como un pensamiento constante que llevas a lo largo del día y de la noche de modo que te acuestas con una pregunta, por ejemplo, de cómo esto se relaciona con lo otro, y te despiertas con la respuesta. Ese hilo va conduciendo tu vida y te va haciendo investigador. Tal vez la palabra "investigador" suene mal, como si fuéramos policías. Te va haciendo una persona comprometida con tu material, con tu ciencia y con la gente de donde provino ese material. Vas adquiriendo esa cualidad social que llaman identidad laboral. Eres una persona rara en el bullicio de la ciudad, pero tú llevas una misión y esa identidad deja de ser laboral únicamente. Esto es muy importante para el tema que tratamos, si es que de verdad nos queremos meter en la investigación con todo el corazón. De paso, ser policía también es una profesión digna, como la de un investigador social.

\section{b. Pasos del análisis}

Pero nos quedamos con los cuadernos en México en la oficina que me prestó el amigo jesuita. ¿Qué pasos seguí en el análisis? Estoy hablando a jóvenes, con sencillez, y voy a bajar a cosas chiquitas que tal vez no tengan que ver con una lección inaugural, pero que muestran cómo la investigación supone una especie de artesanía.

Lo primero que hice fue ordenar todo el material por fechas, los cuadernos, el diario, las hojas, y ponerles número al cuaderno y a cada una de sus páginas. Los estás preparando para el fichaje. Creo que los hojeé subrayando el título de cada entrevista, como para tener una mirada de conjunto. Estás trayendo a la me- moria tu material. Y luego colocas todo en cajas de corn flakes o lo que sea.

Luego, un segundo paso fue releer y fichar todos los cuadernos y el diario de campo. (a) La ficha: yo usaba fichas pequeñas y desechables, para que si quieres ahorrar, no te duela tirar una y otra. Aquí ya entra algo la teoría (las categorías), pero sólo un poco, porque hay tensión entre teoría y dato (abstracción y concreción). En el centro de la ficha, como título, ponía la categoría (ajusticiamiento, carismáticos, tierras, cardamomo...) y abajo una pequeña descripción. En la esquina derecha, el número del cuaderno y la página, y en la esquina izquierda, el lugar y la fecha. (b) El cuaderno: marcaba en el cuaderno con bolígrafo rojo el lugar correspondiente a la ficha. Se va leyendo, marcando y haciendo fichas. Cada ficha, que no te tarde hacerla más de dos o tres minutos. Vas leyendo tu cuaderno, vas haciendo la ficha y vas marcando el cuaderno. Lo que más me costaba a veces era descifrar mi propia letra diminuta y cuasi taquigráfica, como dije. Y según vas avanzando, se va conmoviendo tu corazón, porque vas haciendo presente a la gente que te habló. Pero ojo, no quisiera dar una receta. Solo una experiencia para estrujar tu material como una esponja.

Un tercer paso fue ordenar las fichas. Primero, hacía montoncitos de fichas de las mismas categorías,como ajusticiamientos, carismáticos, emboscadas o de cosas semejantes. Aquí ya interviene un presupuesto teórico (cualitativo): estás utilizando las categorías de la misma gente, ya sea lingüísticamente determinadas o no, que te guían en el entendimiento del proceso social, aunque llegue un momento que la teoría te levante de esas mismas categorías. Segundo, ordenaba los montoncitos y ponía un separador con el título de una categoría más abstracta (comercialización) o una categoría de etapa (propaganda armada, guerra de guerrillas...).

Aquí entra más la teoría (supuestos teóricos): se trataba de una dialéctica, como dijimos, una guerra, con el peligro de caer en la visión de los dos fuegos y olvidar el sujeto, el campesinado indígena. El enfoque, entonces, es diacrónico, histórico: es fácil, sigues la narración de la gente, con la teoría como una sombra vigilante detrás en tu mente. Pero no impones categorías, sino que dejas que el material mismo te las digas. Por eso, si sigues este método de análisis y sistematización, la investigación te sale fresca y nueva, porque no sacas lo que metes, que es la tara de tantas investigaciones que se caen de la mano. 
Todo este proceso de ordenamiento de las fichas es un ejercicio de análisis, porque distingues un dato de otro aplicándole la categoría que te da la gente o la teoría, y es un ejercicio de sistematización, porque vas ordenando las categorías entre sí. Vas armando un edificio. Pero lo importante es que no sea el afán de orden el que te conduzca, sino la dinámica del hilo conductor, que decíamos. El resultado de la investigación será entonces liberador, emancipador, y no regulador, colonizador. Aquí ya tocamos la epistemología.

"Cuando ya tienes tu cajón de fichas ordenadas, ya tienes tu libro", podrías decir, "sólo te falta escribirlo". Esto tiene algo de cierto, pero sólo algo, porque cuando vas escribiendo vas a la vez investigando. La redacción es un proceso creativo. Si no, también es muerta y no comunica vida y se cae de las manos.

\section{c. Planteamiento teórico más explícito}

Según avanzaba en este trabajo, que me duró como mes y medio, recuerdo, fui pensando en el planteamiento teórico más explícito para comenzar la redacción. Consistió en teorías provisionale" sobre levantamientos campesinos desde la visión de una investigación del campesinado salvadoreño (Aguilares y el Paisnal) hecha por Cabarrús (1983), jesuita y antropólogo también. Yo lo acompañé en ese lugar en 1976 pocos meses antes de que asesinaran al padre Rutilio Grande, párroco de esos municipios. Algunos de los factores que él veía, traídos de otros clásicos, para el levantamiento eran: la crisis de la articulación del campesinado al modelo capitalista, la situación del campesino semiproletario, el papel de la vanguardia... Pero para el caso de Ixcán eran provisionales, porque sabía que hay muchas diferencias entre ese caso y el nuestro, como por ejemplo, la que existe entre un campesinado indígena y uno mestizo. Las diferencias le ayudan a uno a pensar. Estas van como hipótesis al principio del volumen tercero y se retoman en las conclusiones.

Pero también utilicé teorías particulares, más aplicadas a Guatemala o a las revoluciones del siglo 20, sobre la insurgencia y la contrainsurgencia. Sobre la insurgencia, el texto de Ramírez (1970), que dio origen al EGP. Y sobre la contrainsurgencia, algunos manuales de experiencias en el sudeste asiático, especialmente el clásico del general inglés Thompson (1974), sobre la contrainsurgencia exitosa y la fracasada, respectivamente en Malaya y Vietnam.
Algunos de los principios de la teoría de la insurgencia eran: (a) la población civil es base de apoyo de la acción militar guerrillera (opuesta a toda concepción de la guerra irregular del foquismo). Es decir, todo el mundo participa en la guerra revolucionaria, que por eso es popular. La base de apoyo da comida a la guerrilla (las mujeres), hacen tareas para ella, como llevar cargas (los hombres), le da información sobre el terreno y sobre el enemigo (todas las personas que puedan), le comunica poder a la organización armada (las estructuras), la abastece con combatientes temporales o permanentesy con cuadros políticos. En esa teoría no se insiste en la distinción entre población civil y militar, pero la supone. (b) La estrategia de comenzar desde la periferia geográfica hasta tomar el poder con una insurrección final en el centro y (c) el ordenamiento de esta estrategia por etapas, como serían, primero la implantación guerrillera, luego la propaganda armada, tercero, la guerra de guerrillas, y por fin la insurrección final. De estas etapas, la fundamental era, me parece, la implantación. Estas etapas con alzas y bajas se dieron en el Ixcán en forma combinada y progresiva con otras zonas del país. La revolución comenzó en Ixcán con el ingreso de los primeros guerrilleros, de allí subió al altiplano, donde se encontró con el movimiento de masas más cercanas a la capital, que con la represión se fueron clandestinizando. Yo fui documentando esta estrategia con los datos del Ixcán, pero mi mirada del enfrentamiento no fue nacional desde muchos puntos, sino sólo desde el Ixcán. Es un rompecabezas que creo yo que ni el Informe Recuperación de la Memoria Histórica (REMHI), ni el Informe Guatemala Memoria del Silencio de la Comisión del Esclarecimiento Histórico (CEH) completaron, como un solo proceso. Creo que estos informes insistieron más en las violaciones de los derechos humanos, que en la dinámica del enfrentamiento. Siempre es un riesgo que lo jurídico meta en "camisa de fuerza" a lo social, cosa que puede suceder con el tratamiento del genocidio.

El ejército utilizaría los mismos principios pero al revés. Primero, impedir la posibilidad de la insurrección en la ciudad descabezando las organizaciones populares abiertas. Segundo, montar un operativo nacional que fuera barriendo a la guerrilla desde el centro hasta la periferia, forzándola a salir por donde había entrado o aniquilándola en el camino. Y tercero, separar a la población de la guerrilla, cosa que hizo utilizando las masacres totales en aldeas escogidas y organizando por la fuerza y el miedo a la población en 
patrullas civiles. Así se reconquistaba el territorio y la población perdida.

Terminé el volumen tercero de la colección que ahora se está publicando. En él no se incluyen ni las masacres, ni el inicio de la resistencia. Más adelante puedo decir una palabra por qué esta estrategia revolucionaria fracasó.

\section{La redacción}

\section{a. Primer momento}

Ahora sigamos con la investigación, enfocando la fase de la redacción. Ya dijimos que cuando se comienza a redactar no se deja de analizar y sistematizar, pero que la redacción implica un aspecto de comunicabilidad: esto que escribo, ¿para quién lo escribo? Lo que averiguaste lo estás trasladando a un público que quieres que comprenda también lo que tú has comprendido. Evidentemente, desde que comienzas la investigación, tienes en mente, como entre sombras, para quién quieres hacer la investigación. Puede ser la institución que te paga. Puede ser un público reducido que quiere conocer para fines prácticos los resultados. Puede ser un público amplio, que es académico o político o de opinión. También, en este caso, consideras que puede haber un público que reaccione en contra y pueda atacarte de diversas formas. Ese era el caso entonces.

\section{b. Notas del segundo momento}

Entonces, después de esa fase de redacción, de 1984 a 1985, existe el presente. Pero decidí que no podía reescribir el volumen, sino solamente añadirle notas críticas desde 2014, indicando puntos en los que me había equivocado. De esa manera se daban dos perspectivas del mismo autor separadas por 30 años y esa reflexión podría servir para la reconciliación necesaria de la sociedad fundada en la autocrítica. Podría servir para animar a otras personas a escribir sus memorias y examinar sus errores

En este escrito no se reflexiona sistemáticamente por qué la teoría revolucionaria fracasó, pero las notas sueltas al pie de la página pueden conducir a tener una idea. Podemos hacer un esfuerzo para entresacarlas, con la provisionalidad del caso que merece más investigación desde distintos puntos de vista y de distintos lugares, y con mucha información más. La razón principal del fracaso es que hubo un error de cálculo político militar de parte de la vanguardia que redundó en las masas, fraguando un triunfalismo mutuo. El pueblo levantado confió que la guerrilla tenía más poder militar del que realmente tenía y la guerrilla confió que el levantamiento popular supliría al poder militar. También hubo un error de cálculo respecto de las barreras humanitarias que el ejército no traspasaría (que no haría masacres masivas), no tanto por razones éticas, sino políticas internacionales. También, no se calculó el poder del ejército de reconquistar terreno y población que había perdido y se pensó que el poder local del ejército descansaba en sus agentes (orejas, comisionados, destacamentos de policía...) y que una vez liquidados estos el ejército no podría volver, como lo hizo, con masacres indiscriminadas ¡ciegas!, porque había perdido los elementos que podrían ayudarle a distinguir a enemigos de personas neutrales y de amigas. A todos acabó. Y después de la barrida fue ganando control con la sistemática organización de patrullas civiles. Tampoco se consideró la alianza del ejército con el poder económico que respecto a la revolución mantuvo una posición unida, a diferencia, por ejemplo, con la empresa privada de Nicaragua, que se dividió, una somocista y otra en contra de Somoza, en apoyo al sandinismo los terceristas.

\section{Conclusiones}

Podríamos seguir adelante con otras fases de la investigación, que, aunque no son propiamente investigación, la determinan, como es la publicación, la promoción y la distribución del texto y la reacción del público en general, sea aprobación o ataques en comentarios. Tratándose de investigación sobre la violencia, amenazas o algo más. Esta experiencia queda para otra ocasión. Y también sería muy importante considerar el financiamiento.

\section{a. La sociedad civil como objeto de estudio}

Con una cosa quiero resumir lo dicho en estas conclusiones. Mi experiencia fue de una investigación, ciertamente cualitativa del enfrentamiento armado y el objeto no fue ni el ejército, ni la guerrilla, sino la población civil, el campesinado indígena, y este como sujeto activo de un levantamiento.

Creo yo que este enfoque puede aplicarse con mucho fruto, aunque con serias dificultades, al estudio de la violencia hoy en día en Guatemala. En un estudio reciente del Instituto de Estudios Estratégicos de Washington menciona que la guerra del narcotráfico 


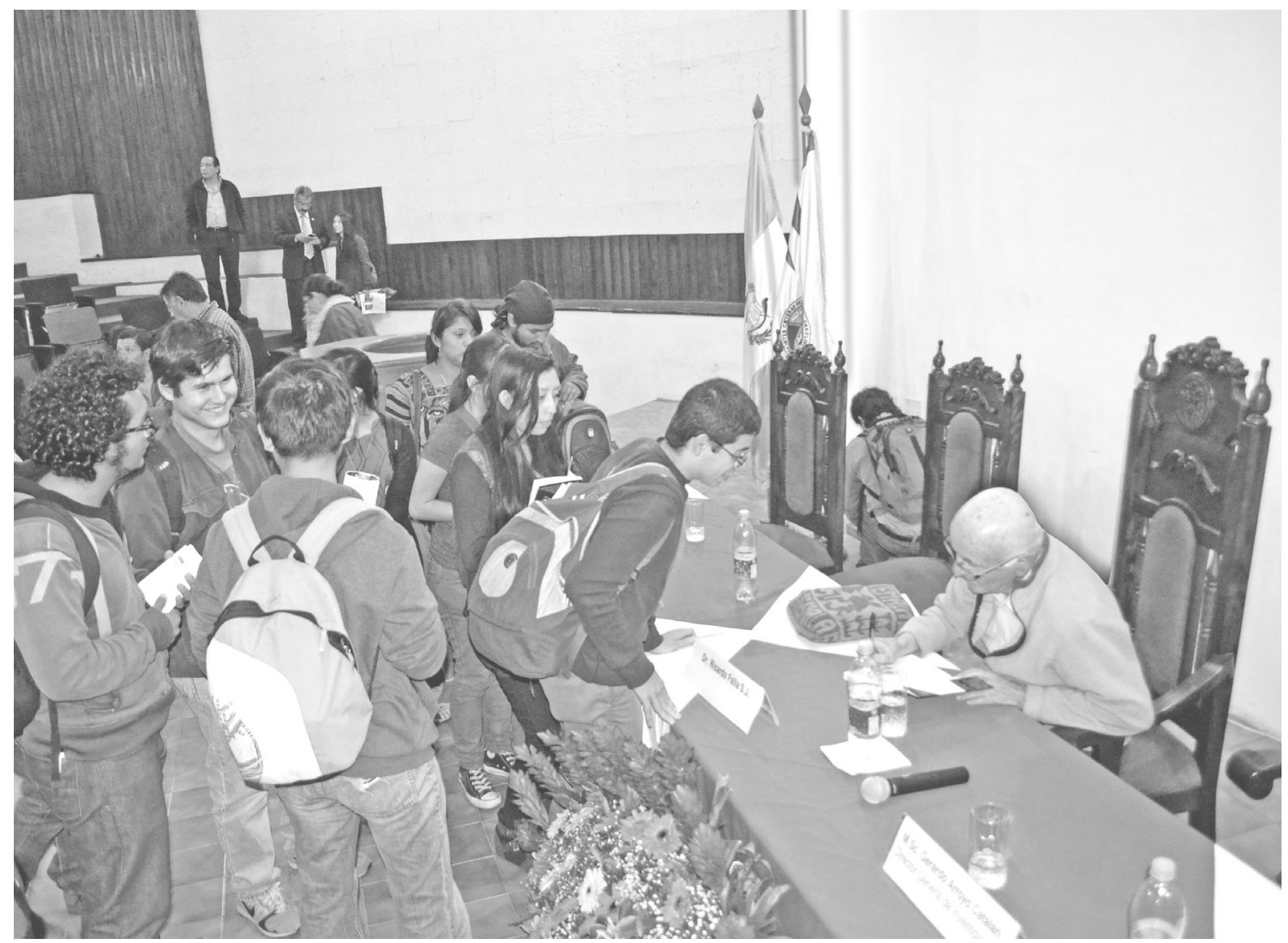

Figura 3. Ricardo Falla rodeado de estudiantes firmando autógrafos al final de su disertación.

incluye tres agentes principales actualmente en Guatemala, (1) las maras o pandillas, (2) los poderes ocultos, y (3) los carteles internacionales del narcotráfico (Brands, 2010). Yo añadiría un cuarto agente que es la sociedad o población civil, ya sea que le dé apoyo local a los carteles, a los poderes ocultos o a las maras y pandillas (muchas veces sus hijos e hijas), ya sea que únicamente sea observadora de lo que sucede en su territorio.

Hay un estudio más reciente, en el 2013 sobre la historia del narcotráfico en México y su autor dice en la introducción que "la historia de la delincuencia organizada no puede entenderse cabalmente sin su compleja relación con la sociedad de la cual es parte", y añade que "por cuestiones de tiempo, este aspecto... no está incorporado en este trabajo" (Valdés, 2013 , p. 27)2. Menciona este aspecto como un factor que propicia la delincuencia. Pero también sucede al

${ }^{2}$ El autor fue titular del Centro de Investigación y Seguridad Nacional (CISEN) durante el gobierno de Felipe Calderón. revés, que el narcotráfico o la delincuencia propicia cambios de muchas formas en la sociedad. Esto suele desconocerse a cabalidad y las políticas se concentran en cómo combatir la delincuencia, sin tener en cuenta la sociedad o población civil que la padece, la encubre o se beneficia de ella. Es tiempo, me parece, de escucharla y oir su punto de vista para entender la dinámica que nos envuelve.

\section{b. Mención de posibles retos de investigación}

Menciono algunos ejemplos para terminar y dejar planteado en concreto el reto de la investigación social, especialmente pero no exclusivamente cualtitativa. Espiguemos casos. Veamos las noticias recientes de Tajumulco e Ixchiguán en San Marcos, donde el ejército ha instalado recientemente un destacamento, para poner paz, dice, entre las dos comunidades. En realidad vemos que es para respaldar la erradicación 
de miles de matas de amapola con la que se hace el opio y la heroína (Marroquín, 2015). Allí, los miles de productores que se quedan sin las ganancias de su cultivo es la sociedad civil, que busca ese cultivo para salir de la pobreza. Allí hay un terreno necesitado de una investigación arriesgada para conocer las dinámicas que se mueven y las soluciones. No sería el foco del estudio el ejército, ni la policía, ni los carteles, ni los poderes ocultos, sino la población civil, desde la cual la investigación mirará al ejercito, a los carteles y a los poderes ocultos.

$\mathrm{O}$, saltando al oriente, recordemos cómo hace año y medio (Prensa Libre, 2013) "una turba de al menos 500 personas liberó ayer de manos de la Policía Nacional Civil (PNC) a José Ranferí Ponce Rodríguez", hermano de un narcotraficante que cumple condena en los EE.UU. Esto sucedió en una pequeña aldea de Morales, Izabal. "La turba" que se levanta para liberar a José Ranferí era población civil. La prensa la denigra con ese apelativo. ¿Cuáles son sus motivos?, ¿cuáles es "la compleja relación" entre los comunitarios y el capo? El ministro de Gobernación declaró entonces que los 15 policías que habían intervenido en la captura no podían haber disparado contra la gente, porque habría sido una masacre. Reconoce, por lo menos, la diferencia entre población civil y narcotraficantes armados, pero quedamos en la ignorancia de la dinámica de población y qué motivo la apega al capo.

Y no muy lejos de este lugar, también en el oriente, Los Amates, Izabal, de donde provenían los 27 trabajadores agrícolas, población civil, que fueron asesinados en la finca Los Cocos, en La Libertad, Petén (Prensa Libre 14-5-2011). A principios del año pasado fueron juzgados nueve responsables de dicha masacre. En las declaraciones de los testigos aparecen destellos de información sobre la colaboración de la población civil con el narcotráfico, aunque esta, según los Zetas asesinos, no fueran agricultores de la finca, sino organizados en el Cartel del Golfo que se encargaban de "pasar la droga a México". Algunos de los testigos en el juicio se declararon simplemente colaboradores de los asesinos, por ejemplo, en la función de chofer y guía de terreno (Prensa Libre, 23-1-2014). Los periodistas que sacan estas noticias son investigadores, pero se concentran en averiguar sobre los contendientes, el narcotráfico y las fuerzas del gobierno. La población civil, se deja a un lado, como si fuera pasiva o se la identifica con los carteles peligrosamente. Otro es el caso de la población civil de los barrios y de barrancos que cruzan la ciudad de Guatemala, donde se mueven las maras, enfrentadas entre sí y conectadas al crimen organizado (redes de extorsionistas y de narcotraficantes). Si los miembros de las maras no son población civil, se ven al menos protegidos por sus padres y madres, hermanos y hermanas, quienes sí son claramente comunitarios, que de forma indirecta se ven afectados por la existencia de estas pandillas. Como investigadores sociales no nos interesa conocer su dinámica para neutralizarlos, denunciarlos o capturarlos. Esa es tarea de la Policía y del Ministerio Público (MP). Nos interesa para apoyar con su voz a la defensa de sus derechos y para conocer las fuerzas que pueden tener para la pacificación de sus colonias.

Así termino esta ponencia. Me he alargado un poco, pero quería exponer mi experiencia en la investigación del enfrentamiento armado para que la juventud se anime a aplicar sus conocimientos a escuchar a la población guatemalteca inmersa hoy en otras clases de violencias y buscar con la ayuda de su visión algunas formas para alcanzar la paz.

\section{Referencias}

Brands, H. (2010). Crime, Violence and the Crisis in Guatemala: A case study in the erosion of the State. Carlisle, PA: Strategic Studies Institute.

Cabarrús, C. R. (1983). Génesis de una revolución. Análisis del surgimiento y desarrollo de la organización campesina en El Salvador. México: Centro de Investigaciones y Estudios Superiores de Antropología Social.

Hernández, S. J. (2014). Luchar por la justicia al viento del espiritu. Autobiografia y esbozo de historia de mi generación. San Salvador, El Salvador: UCA Editores.

Marroquín, A. (8 de enero de 2015). Militarizan zona de conflicto territorial. Prensa Libre. Recuperado de http://www.prensalibre.com/san_marcos/San Marcos-Ejercito_0_1280872160.html\#comments

Prensa Libre. (16 de octubre de 2013). Izabal. Población libera a supuesto narcotraficante tras captura en Morales. Guatemala. Recuperado de http://www.prensalibre.com/izabal/capturashermanos-narcotrarficante-Ponce_RodriguezMorales-Izabal_0_1012098945.html

Ramírez, R. (1970). La situation du mouvement guatémalteque et ses perspectives. En Lettres $d u$ front guatémalteque (pp. 107-160). Paris: François Maspero. 
Thompson, R. (1974). Defeating Communist Insurgency: Experiences from Malaya and Vietnam. London: Chatto and Windus.

Valdés, G. (2013). Historia del narcotráfico en México. México: Aguilar 